\title{
Hemşirelik Girişimleri İkincil Beyin Hasarına Neden Olabilir mi?
}

\author{
Gülay Altun Uğraş ${ }^{1} \oplus$, Canan Kanat ${ }^{1} \oplus$
}

Mersin Üniversitesi, Hemşirelik Fakültesi, Mersin, Türkiye

Gülay Altun Uğraş, Dr. Öğr. Üyesi Canan Kanat, Araş. Gör.

\section{İletişim:}

Dr. Öğr. Üyesi Gülay Altun Uğraş Mersin Üniversitesi, Hemşirelik Fakültesi, Mersin, Türkiye Tel: +903243610001

E-Posta: gulay.altun@yahoo.com
Gönderilme Tarihi : 28 Mayıs 2017 Revizyon Tarihi : 23 Haziran 2017 Kabul Tarihi : $\quad 28$ Haziran 2017
ÖZET

İkincil beyin hasarı; kafa içi basınç artışı, serebral perfüzyon basıncında azalma, hipotansiyon ve serebral kan akımında azalma sonucu meydana gelmektedir. Nöroşirürji hastalarında tedavi ve hemşirelik bakımının odak noktası kafa içi basınç artışını önlemektir. Ancak bazı hemşirelik girişimleri de ikincil beyin hasarına neden olabilmektedir. Endotrakeal aspirasyon, ağız bakımı, vücut banyosu, hastayı döndürme ya da yeniden pozisyon verme ve hemşirelik girişimlerinin bir araya toplanması gibi rutin uygulanan hemşirelik girişimleri, serebral metabolizma hızını arttırdığı, serebral perfüzyon basıncını azalttığı ve serebral kan akımını etkileyerek, ikincil beyin hasarına yol açabilmektedir. Bu sistematik derlemede, nöroşirürji hastalarında ikincil beyin hasarına neden olabilecek hemşirelik girişimlerini güncel literatür eşliğinde irdelemek ve hemşirelere ikincil beyin hasarının önlenmesine yönelik rehberlik edecek bilgiler sunmak amaçlandı.

Anahtar sözcükler: İkincil beyin hasarı, hemşirelik girişimleri, kafa içi basınç, serebral perfüzyon basıncı

\section{COULD NURSING INTERVENTIONS CAUSE SECONDARY BRAIN INSULT?}

\section{ABSTRACT}

As a result of increase in intracranial pressure, decrease in cerebral perfusion pressure, hypotension and decrease in cerebral blood flow secondary brain insult may occur. The main focus of treatment and nursing care in neurosurgical patients is to prevent intracranial pressure increase. But some nursing interventions can also cause secondary brain damage. Routine nursing interventions such as endotracheal suction, oral care, body bath, rotationing and repositioning of patients and clustering of nursing interventions may cause secondary brain insult by increasing cerebral metabolism rate, decreasing cerebral perfusion pressure and affecting cerebral blood flow. This systematic review aims to provide guidance to nurses about the prevention of secondary brain insult by reviewing the nursing interventions that may cause secondary brain insult in neurosurgical patients in the light of current literature.

Keywords: Secondary brain insult, nursing interventions, intracranial pressure, cerebral perfusion pressure

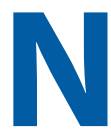

öroşirürji hastalarında, kafa içi basınç (KIB) artışı, düşük serebral perfüzyon basıncı (SPB), hipotansiyon ve serebral kan akımında azalma, ikincil beyin hasarına neden olabilmektedir (1). Normal koşullar altında, KiB'ı yetişkinlerde 0-15 mmHg; SPB'ı ise 70-100 mmHg aralığındadır (2). Hiperkarbi, hipoksemi, endotrakeal aspirasyon, bazı beden pozisyonları, izometrik kas kontraksiyonları (hastanın ayaklarıyla yatağı itmesi, titreme, dekortikasyon, deserebrasyon vb.), valsalva manevrası (kusma, ıkınma, öksürme, hapşırma, lavman vb.), ağıılı uyaranlar (invaziv girişimler vb.), serebral metabolizmayı arttıran aktiviteler (nöbet, hipertermi, vb.), tedavi ve bakım girişimlerinin bir araya toplanması, KiB'ı etkileyen ve artışına neden olan faktörlerdir (3). 
İkincil beyin hasarları, gerekli tedavi ve bakım girişimleri ile önlenebilir ve geri döndürülebilir durumlardır (4). Nöroşirürji hastalarında tedavi ve hemşirelik bakımının amacı, KIB ve SPB'ını normal sınırlar içerisinde tutarak ikincil beyin hasarını önlemek ya da en aza indirmektir. Buna karşın bazı hemşirelik girişimleri ikincil beyin hasarına neden olabilmektedir (5-7).

Nöroşirürji hemşirelerinin sorumluluğu; hastanın gereksinimi olan bakımı verirken hastanın güvenliğini de sağlamaktır (8). Rutin olarak uygulanan hemşirelik girişimleri, serebral metabolizma hızını arttırarak beyne giden kan akımını ve beraberinde serebral kan hacmini arttırmaktadır. Bu artış, KiB'ın yükselmesine ve SPB'ın düşüşüne neden olmakta ve ikincil beyin hasarı ile sonuçlanabilmektedir $(3,5,9)$. Hemşirelik girişimlerinden sonra 5 dakika ya da hemşirelik girişiminin başlamasından itibaren 10 dakikadan uzun süren, KiB'ın 20 mmHg üstünde, SPB'ın $60 \mathrm{mmHg}$ altında ve sistolik kan basıncının 100 $\mathrm{mmHg}$ altında seyretmesi, ikincil beyin hasarı meydana getirebilmektedir (6).

Bu sistematik derlemede; nöroşirürji hastalarında ikincil beyin hasarına neden olabilecek hemşirelik girişimleri güncel literatür eşliğinde irdelenerek, nörojişürji hastalarına verilen bakımı kanıt temelli uygulamalarla desteklemek amacıyla hemşirelere ikincil beyin hasarının önlenmesine yönelik rehberlik edecek bilgiler sunuldu. Bu doğrultuda derleme, 2002 ve 2017 yılları arasında PubMed, ScienceDirect, Cochrane, EbscoHostDynamed, EbscoHostHealth Source, Ovid LWW Journals, Springer Link, Google Scholar ve ULAKBIM veri tabanlarından elde edilen tam metin derlemeler ve araştırmalar, nöroşirurji alanına özgü yazıımış kitaplar ile çeşitli dernek ve kuruluşların oluşturduğu klinik rehberler incelenerek oluşturuldu. Literatür taramasında, KiB artışı, SPB, ikincil beyin hasarı, endotrakeal aspirasyon, hastaya pozisyon verme, ağız bakımı, vücut banyosu, hemşirelik girişimleri gibi anahtar kelimeler kullanıldı.

\section{İkincil beyin hasarına neden olabilecek hemşirelik girişimleri}

Endotrakeal Aspirasyon: Endotrakeal aspirasyon mekanik ventilatör desteği alan nöroşirürji hastalarında, KiB artışına neden olan hiperkarbi ve hipoksiyi önlemek amacıyla uygulanan rutin bir hemşirelik girişimidir. Endotrakeal aspirasyon, solunum yollarında biriken sekresyonun neden olduğu karbondioksit $\left(\mathrm{CO}_{2}\right)$ düzeyini düşürerek KiB artışını önlemektedir $(3,10,11)$.
Beyin Travma Derneği tarafından yayınlanan rehberlerde; parsiyel karbondioksit basınc $\left(\mathrm{PaCO}_{2}\right) 35-40 \mathrm{mmHg}$ (12), parsiyel oksijen basınc $\left(\mathrm{PaO}_{2}\right) 60$ mmHg'nın üstünde ve arteriyel oksijen saturasyonunun $\% 90$ ve üzerinde olması önerilmektedir (13). PaCO 'nda artış, beyin damarlarında vazodilatasyona, $\mathrm{PaO}_{2}$ 'nda azalma ise anaerobik metabolizmayı başlatarak laktik asit miktarının artmasına ve beraberinde vazodilatasyona neden olmaktadır. Beyin damarlarında vazodilatasyon ise serebral kan hacmini arttırarak, KIB'ta artışa ve SPB'nda düşüşe yol açmaktadır $(2,10,11)$.

Endotrakeal aspirasyon, yüksek $\mathrm{CO}_{2}$ düzeyinin düşmesini sağlayarak KiB artışını önlerken işlemin kendisi KiB artışına neden olabilmektedir $(11,14)$. Endotrakeal aspirasyon sırasında KiB artışı ve SPB'nda azalma iki mekanizma sonucu meydana gelmektedir. İlk mekanizma, endotrakeal aspirasyon işlemi öncesi ve sonrası hastanın ventilatörden ayrılması ve hastanın tekrar ventilatöre bağlanması nedeniyle ortaya çıkar. Bu işlem endotrakeal tüp hareketine yol açarak, trakeal ve larengeal afferent sinirleri uyarıp öksürüğe neden olmaktadır. Öksürük sonucu valsalva manevrası gelişmekte, intratorasik ve intraabdominal basıncı geçici olarak attırmakta ve bu durum KiB artışı meydana getirmektedir $(3,14,15)$.

İkinci mekanizma ise, endotrakeal aspirasyon sırasında mekanik ventilasyona ara verilmesi ve sekresyonla birlikte oksijenli havanın çekilmesi ile ortaya çıkan hipoksemidir. Hipoksemi, $\mathrm{PaO}_{2}$ 'nda düşmeye ve $\mathrm{PaCO}_{2}$ 'nda artışa neden olarak serebral vazodilatasyona neden olmaktadır. Serebral vazodilatasyon, serebral kan akımını beraberinde KiB'ı arttırmaktadır $(3,11,15)$. Hipoksemi riskini en aza indirmek amacıyla; aseptik teknikle yapılan aspirasyondan önce, aspirasyon girişimleri arasında ve aspirasyondan sonra hastaya \%100 oksijen verilmelidir. Her endotrakeal aspirasyon uygulamasında kateter girişi, 2 defa ile sınırlandırımalı ve her girişin süresi 10 saniyeyi geçmemelidir (3).

Günümüzde endotrakeal aspirasyon, açık ve kapalı sistem olmak üzere iki yöntemle yapılmaktadır. Açık sistem endotrakeal aspirasyonda, hastanın ventilatör ile bağlantısı kesilirken, kapalı sistem endotrakeal aspirasyonda, hastanın ventilatör ile bağlantısı kesilmemekte ve oksijenasyonu sürdürülmektedir $(10,11,16)$.

Açık ve kapalı endotrakeal aspirasyonun KIB ve SPB üzerine etkisini inceleyen çalışmalar Tablo 1'de yer almaktadır $(10,11,14,17-25)$. Bu çalışmaların sonucuna göre; endotrakeal aspirasyon geçici ancak anlamlı bir KiB artışı ve SPB azalmaya neden olmaktadır $(11,14,17,22,25)$. Kapalı sistem aspirasyon açık sistem aspirasyonuna göre daha 


\begin{tabular}{|c|c|c|c|c|}
\hline Çalışma & $\begin{array}{l}\text { Çalışmanın } \\
\text { Yöntemi }\end{array}$ & $\begin{array}{l}\text { Kanıt } \\
\text { Düzeyi }\end{array}$ & $\begin{array}{c}\text { Öneri } \\
\text { Derecesi }\end{array}$ & $\begin{array}{l}\text { Çalışma } \\
\text { Sonuçları }\end{array}$ \\
\hline Gemma ve ark. (14) & $\begin{array}{l}\text { Yarı deneysel } \\
\text { klinik çalışma } \\
\text { (17 hasta) }\end{array}$ & $2 b$ & B & $\begin{array}{l}\text { Çalışmada açık sistem endotrakeal aspirasyon yönteminin KiB ve SPB üzerine } \\
\text { etkisi araştııımışır. Açık sistem endotrakeal aspirasyonun klinik olarak anlamlı bir } \\
\text { KiB artışı ve SPB'nda azalmaya neden olduğu, öksürme refleksi olan hastalarda bu } \\
\text { değişiklikleri azaltmak için aspirasyon sırasında sedasyon düzeyinin arttırlabileceği } \\
\text { bildirilmiştir. }\end{array}$ \\
\hline Thiesen ve ark. (17) & $\begin{array}{l}\text { Prospektif, } \\
\text { girişimsel çalışma } \\
\text { (35 hasta) }\end{array}$ & $2 a$ & B & $\begin{array}{l}\text { Çalışmada açık sistem endotrakeal aspirasyon yönteminin KiB ve SPB üzerine } \\
\text { etkisi araştıılmıştır. Açık sistem endotrakeal aspirasyon sırasında, KiB'ın arttığı ve } \\
\text { SPB'nın azaldığı bildirilmiştir. }\end{array}$ \\
\hline Leone ve ark. (18) & $\begin{array}{l}\text { Klinik deneysel } \\
\text { çalışma } \\
\text { (20 hasta) }\end{array}$ & $2 a$ & B & $\begin{array}{l}\text { Çalışmada açık sistem endotrakeal aspirasyon yönteminin KiB ve SPB üzerine } \\
\text { etkisi araştııımıştır. Açık sistem endotrakeal aspirasyon uygulamasında KIB'ı } \\
\text { azaltmak için } 3 \text { doz remifentanil verilen hatalarda, aspirasyon sırasında KiB basınç } \\
\text { artışı görüldüğü, SPB'nın ise değişmediği bildirilmiştir. }\end{array}$ \\
\hline Chivite Fernandez ve ark. (19) & $\begin{array}{l}\text { Klinik deneysel } \\
\text { çalışma } \\
\text { (13 hasta) }\end{array}$ & $2 a$ & B & $\begin{array}{l}\text { Çalışmada açık sistem endotrakeal aspirasyon yönteminin KiB ve SPB üzerine } \\
\text { etkisi araştıılmıştır. Açık sistem endotrakeal aspirasyon sırasında kas gevşetici } \\
\text { uygulanan grupla, uygulanmayan gruba ait KiB ve SPB değerleri arasında anlamlı } \\
\text { bir fark bulunduğu, endotrakeal aspirasyon öncesi kas gevşetici uygulanan } \\
\text { hastalarda daha az KiB artışı gözlendiği bildirilmiştir. }\end{array}$ \\
\hline Bilotta ve ark. (20) & $\begin{array}{l}\text { Klinik deneysel } \\
\text { çalışma } \\
\text { (41 hasta) }\end{array}$ & $2 a$ & B & $\begin{array}{l}\text { Çalışmada kapalı sistem endotrakeal aspirasyon yönteminin KiB ve SPB üzerine } \\
\text { etkisi araştırımışıtı. Kapalı sistem endotrakeal aspirasyon sırasında endotrakeal } \\
\text { tüp içine damlatılan lidokainin KiB artışını etkili bir şekilde önlediği ve SPB'nı ise } \\
\text { değiştirmediği bildirilmiştir. }\end{array}$ \\
\hline Hickey ve Olson (21) & $\begin{array}{l}\text { Gözlemsel çalışma } \\
\text { (5 hasta) }\end{array}$ & 3 & C & $\begin{array}{l}\text { Çalışmada açık sistem endotrakeal aspirasyon yönteminin KiB üzerine etkisi } \\
\text { araştııımıştır. Açık sistem endotrakeal aspirasyon sırasında KiB artışının } \\
20 \text { mmHg'ye ulaşmadığı bildirilmiştir. }\end{array}$ \\
\hline Gholamzadeh\& Javadi (22) & $\begin{array}{l}\text { Klinik deneysel } \\
\text { çalışma } \\
\text { (21 hasta) }\end{array}$ & $2 a$ & B & $\begin{array}{l}\text { Çalışmada açık sistem endotrakeal aspirasyon yönteminin KiB üzerine etkisi } \\
\text { araş̧ıııımıştır. Açık sistem endotrakeal aspirasyon sırasında KiB’ta artış olduğu, } \\
\text { aspirasyon kateterinin 4. girişinde meydana gelen artışın önceki girişlere göre } \\
\text { anlamlı derecede daha yüksek olduğu bildirilmiştir. }\end{array}$ \\
\hline Nemer ve ark. (23) & $\begin{array}{l}\text { Klinik deneysel } \\
\text { çalışma } \\
\text { (60 hasta) }\end{array}$ & $2 a$ & B & $\begin{array}{l}\text { Çalışmada açık sistem endotrakeal aspirasyon ile kapalı sistem endotrakeal } \\
\text { aspirasyon yöntemlerinin KiB ve SPB üzerine etkisi araştııımıştır. Endotrakeal } \\
\text { aspirasyonun anlamlı derecede KiB artışı ve SPB'nda azalmaya neden olduğu, } \\
\text { açık sistem endotrakeal aspirasyonda KiB'ın } 20 \text { mmHg yüksekliğe ulaştığı ancak } \\
\text { kapalı sistem endotrakeal aspirasyonda KiB'ın } 20 \text { mmHg yüksekliğe ulaşmadığı } \\
\text { bildirilmiştir. }\end{array}$ \\
\hline Cerqueira-Neto ve ark. (24) & $\begin{array}{l}\text { Prospektif, klinik } \\
\text { deneysel çalışma } \\
\text { (20 hasta) }\end{array}$ & $2 a$ & B & $\begin{array}{l}\text { Çalışmada açık sistem endotrakeal aspirasyon yönteminin KiB ve SPB üzerine } \\
\text { etkisi araştırılmıştı. Açık sistem endotrakeal aspirasyon sırasında KiB'ta artış } \\
\text { olduğu ve bu değerlerin işlem sonrası } 10 \text { dakika içinde işlem öncesine döndüğü } \\
\text { bildirilmiştir. }\end{array}$ \\
\hline Altun Uğraş ve Aksoy (11) & $\begin{array}{l}\text { Çapraz kontrollü tek } \\
\text { kör klinik çalışma } \\
\text { (32 hasta) }\end{array}$ & $2 \mathrm{a}$ & B & $\begin{array}{l}\text { Çalışmada açık sistem endotrakeal aspirasyon ile kapalı sistem endotrakeal } \\
\text { aspirasyon yöntemlerinin KiB ve SPB üzerine etkisi araştırılmıştı. Açı ve kapalı } \\
\text { sistem endotrakeal aspirasyonun KiB artışı ve SPB'ında azalmaya neden olduğu } \\
\text { ancak, kapalı sistem endotrakeal aspirasyonun KiB ve SPB'nı daha az etkilediği } \\
\text { bildirilmiştir. }\end{array}$ \\
\hline Mathieu ve ark. (25) & $\begin{array}{l}\text { Prospektif, klinik } \\
\text { deneysel çalışma } \\
\text { (15 hasta) }\end{array}$ & $2 a$ & B & $\begin{array}{l}\text { Çalışmada kapalı sistem endotrakeal aspirasyon yönteminin KiB ve SPB üzerine } \\
\text { etkisi araştırımış̧ı. Kapalı sistem endotrakeal aspirasyon sırasında kullanılan } \\
\text { aerosol lidokainin tek başına KiB artışını önlemediği, aspirasyon sırasında KiB } \\
\text { artışı ve SPB'nda azalma olduğu bildirilmiştir. }\end{array}$ \\
\hline Galbiati ve Paola (10) & $\begin{array}{c}\text { Derleme } \\
\text { (14 çalışma) }\end{array}$ & $1 a$ & A & $\begin{array}{l}\text { Çalışmada, endotrakeal aspirasyon (açık ve/veya kapalı sistem aspirasyon } \\
\text { yöntemi) uygulanan } 14 \text { çalışmanın sonucu incelenmiş ve aspirasyonun KiB ve } \\
\text { SPB'ı üzerine etkisi araştııııışı.ı. İncelenen çalışmalarda açıı ve kapalı sistem } \\
\text { endotrakeal aspirasyonun, işlem sırasında KỉB artırırdığı; çalışmaların çoğunda açık } \\
\text { sistem aspirasyonun KiB'ı } 20 \text { mmHg'nın üzerine çıkardığı bildirilmiştir. Derlemede, } \\
\text { her iki aspirasyon yönteminin SPB üzerindeki etkisi ile ilgili, tutarsı sonuçlar } \\
\text { olduğu da ifade edilmiştir. }\end{array}$ \\
\hline
\end{tabular}


az KIB artışı ve SPB'nda azalma meydana getirmektedir $(11,23)$. Endotrakeal aspirasyon önerilen standartlara uygun yapıldığında, güvenli bir uygulama olup ikincil beyin hasarına neden olmayabilir.

\section{Hastayı Döndürme/Yeniden Pozisyon Verme:} Nöroşirürji hastalarına daha iyi bir bakım ve konfor sağlamak için farklı baş elevasyonu ve beden pozisyonları verilmelidir (26,27). Hastalarda KiB artışına yol açan pozisyonlar ise; trandelenburg pozisyonu, prone pozisyonu, abdomene doğru kalçanın aşırı fleksiyonu ve boynun rotasyonu, fleksiyonu ve ekstansiyonudur $(3,28)$. Bu beden pozisyonları; intraabdominal ve intratorasik basınç artışına, boyunda basınç ve tıkanıklığa ya da venöz dönüşü bozabilecek herhangi bir duruma neden olarak kanın intrakraniyal kavite içerisinde kalmasına yol açmaktadır. Kanın intrakraniyal kavite içinde kalması serebral kan hacminin arttırarak KIB'ı arttırmaktadır $(21,26,29)$.
Nöroşirürji hastalarına farklı pozisyonlar verilerek KIB ve SPB üzerine etkisini inceleyen çalışmalar Tablo 2'de yer almaktadır (1,6,26,30-33). Yatak başı kaldıılarak verilen lateral pozisyon (26), başın uzun süreli fleksiyon ve ekstansiyonu (serebral kan akımını değiştirdiğinden) (32), başın $45^{\circ}$ yükseltilmesi (31), nöroşirürji hastaları için zararlı olabilecek pozisyonlardır. Hastanın döndürülmesi ya da yeniden pozisyon verilmesi sırasında ve verilen bazı pozisyonlarda, geçici ancak anlamlı bir KiB artışı ve SPB düşüklüğüne neden olmaktadır (26,30-32), Ayrıca, döndürme ya da yeniden pozisyon verme, hastalara uygulanan diğer hemşirelik girişimlerine göre KiB'ı arttırarak, daha fazla ikincil beyin hasarı (\%7) meydana getirmektedir (6).

Ağız Bakımı: Nöroşirürji hastalarının hijyenik gereksinimlerinden birisi de ağız bakımıdır. Ancak ağız bakımı sırasında oluşabilecek iki mekanizma, KiB artışına neden

Tablo 2. Döndürme/yeniden pozisyon vermenin kafa içi basınç ve serebral perfüzyon basıncı üzerine etkisini inceleyen çalışmalar

\begin{tabular}{|c|c|c|c|c|}
\hline Çalışma & $\begin{array}{c}\text { Çalışmanın } \\
\text { Yöntemi }\end{array}$ & $\begin{array}{l}\text { Kanıt } \\
\text { Düzeyi }\end{array}$ & $\begin{array}{c}\text { Öneri } \\
\text { Derecesi }\end{array}$ & Çalışma Sonuçları \\
\hline Ng ve ark. (30) & $\begin{array}{l}\text { Klinik deneysel } \\
\text { çalışma } \\
\text { (38 hasta) }\end{array}$ & $2 a$ & B & $\begin{array}{l}\text { Çalışmada baş elevasyonunun }\left(0^{\circ}-30^{\circ}\right) \text {, KiB ve SPB üzerine etkisi araşı̧ııımıştır. Ciddi } \\
\text { travmatik beyin yaralanmalı hastalarda, yatak başının } 30^{\circ} \text { den } 0^{\circ} \text { ye düşürülmesinin KiB } \\
\text { artışına ve SPB'nda azalmaya neden olduğu bildirilmiştir. }\end{array}$ \\
\hline Palazón ve ark. (31) & $\begin{array}{l}\text { Klinik deneysel } \\
\text { çalışma } \\
\text { (10 hasta) }\end{array}$ & $2 a$ & B & $\begin{array}{l}\text { Çalışmada baş elevasyonunun }\left(30^{\circ}-45^{\circ}\right) \text { KIB ve SPB üzerine etkisi araştııılmıştır. } \\
\text { Serebral kanamalı hastalarda, baş yüksekliği } 30^{\circ} \text { 'den } 45^{\circ} \text { ye yükseltildiğinde KiB azalma } \\
\text { olduğu ancak } 30^{\circ} \text { ye göre } 45^{\circ} \text { yükseklikte SPB'nın anlamlı oranda daha düşük olduğu } \\
\text { bildirilmiştir. }\end{array}$ \\
\hline Ledwith ve ark. (26) & $\begin{array}{l}\text { Yarı deneysel } \\
\text { klinik çalışma } \\
\text { (33 hasta) }\end{array}$ & $2 b$ & B & $\begin{array}{l}\text { Çalışmada hastalara farkı derecelerde }\left(15^{\circ}-30^{\circ}-45^{\circ}\right) \text { verilen supine, sol lateral, sağ } \\
\text { lateral ve diz elevasyonu pozisyonlarının, KiB ve SPB üzerine etkisi araştııımıştır. } \\
\text { Supine } 45^{\circ} \text {, sol lateral } 15^{\circ} \text {, sağ lateral } 15^{\circ} \text { pozisyonları anlamlı bir KiB artışına, sol lateral } \\
30^{\circ} \text { anlamlı bir SPB'da azalmaya neden olduğu ve yatak başı kaldııımadan verilen lateral } \\
\text { pozisyonun, nöroşirürji yoğun bakım ünitesinde yatan (travmatik beyin yaralanması, } \\
\text { subaraknoid beyin kanaması, tümör rezeksiyonu) hastalar için en zararlı pozisyon olduğu } \\
\text { bildirilmiştir. }\end{array}$ \\
\hline Kose ve Hatipoğlu (32) & $\begin{array}{l}\text { Klinik deneysel } \\
\text { çalışma } \\
\text { (38 hasta) }\end{array}$ & $2 a$ & B & $\begin{array}{l}\text { Çalışmada, supine pozisyonunda baş elevasyonunun }\left(0^{\circ}-30^{\circ}\right) \text {; sol ve sağ lateral } \\
\text { pozisyonlarda baş elevasyonun }\left(30^{\circ}\right) \text {; sağ ve sol lateral pozisyonda hastanın } 30^{\circ} \\
\text { baş elevasyonunda iken fleksiyon ve ekstansiyonunun, serebral kan akımına etkisi } \\
\text { araştııııış̦tı. Başın uzun süreli fleksiyon ve ekstansiyonunun serebral kan akımını } \\
\text { değiştirdiği için kraniyal cerrahi girişim geçiren hastalara bu pozisyonların verilmemesi } \\
\text { gerektiği, optimum serebral kan akımını sağlamak için baş elevasyonunun } 30^{\circ} \text { olması } \\
\text { gerektiği, sağ ve sol lateral pozisyonun tıbbi bir kontrendikasyon yoksa bu hastalar için } \\
\text { güvenilir olduğu bildirilmiştir. }\end{array}$ \\
\hline Jiang ve ark. (33) & $\begin{array}{l}\text { Meta-analiz } \\
\text { (10 çalışma) }\end{array}$ & $1 \mathrm{a}$ & A & $\begin{array}{l}\text { Çalışmada, farklı derecelerde }\left(0^{\circ}-10^{\circ}-15^{\circ}-30^{\circ}-45^{\circ}\right) \text { baş elevasyonu uygulanan } \\
10 \text { çalışmanın sonucu incelenmiş ve bu pozisyonların KiB üzerine etkisi araştıııımışı̧ı. } \\
\text { Hastalara verilen farklı derecelerdeki baş elevasyonu birbiri ile karşılaştııılarak, KiB'ının } \\
\text { azaltılmasında optimum baş yüksekliğinin } 30^{\circ}-45^{\circ} \text { olduğu bildirilmiştir. Ancak verilen } \\
\text { pozisyonların SPB'na etkisi bu çalışmada incelenmemiştir. }\end{array}$ \\
\hline Nyholm ve ark. (1) & $\begin{array}{l}\text { Kantitatif prospektif } \\
\text { gözlemsel çalışma } \\
\text { (28 hasta) }\end{array}$ & 3 & C & $\begin{array}{l}\text { Çalışmada supine, sağ ve sol lateral pozisyonlarının KiB üzerine etkisi araştııımıştır. } \\
\text { Lateral pozisyondan supine pozisyonuna getirilen hastaların 4'ünde, supine } \\
\text { pozisyonundan lateral pozisyona getirilen hastaların 1'inde KiB artışı bildirilmiştir. }\end{array}$ \\
\hline Nyholm ve ark. (6) & $\begin{array}{l}\text { Kantitatif prospektif } \\
\text { gözlem çalışması } \\
\text { (18 hasta) }\end{array}$ & 3 & C & $\begin{array}{l}\text { Çalışmada yeniden pozisyon vermenin KiB ve SPB'ı üzerine etkisi araştııımıştır. } \\
\text { Hastalara } 571 \text { kez pozisyon değişimi yapılmış ve pozisyon değişimi sonrası; } 39 \text { girişimde } \\
\text { KiB’ta artış, } 19 \text { girişimde SPB'nda azalma meydana gelmiştir. Çalışmada hemşirelik } \\
\text { girişimleri arasında en fazla ikincil beyin hasarına, yeniden pozisyon vermenin neden } \\
\text { olduğu bildirilmiştir. }\end{array}$ \\
\hline
\end{tabular}


olmaktadır. Bunların ilki; ağız bakımı sırasında ağız boşluğu, dudaklar ve yüzde meydana gelen duyusal uyarıların, serebral korteksi (5., 7., 9., 10. kraniyal sinirlerle) uyarmasıdır. Serebral korteksin uyarılması serebral metabolizmayı beraberinde serebral kan akımını arttırmaktadır. Serebral kan akımındaki bu artış, serebral kan hacminde ve sonrasında Kỉ'da artışa yol açmaktadır. İkinci mekanizma ise; endotrakeal tüp manipülasyonu ve boyun bölgesine uygulanan pozisyonun neden olduğu ağrı ve rahatsızıktır. Bu duyusal uyaranlar otonom sinir sistemini uyararak kan basıncını yükseltmektedir. Kan basıncındaki bu artış, serebral kan akımında ve KiB'da artışa yol açmaktadır $(5,35)$.

Nöroşirürji hastalarına verilen ağız bakımının KiB ve SPB'na etkisini inceleyen çalışmalar Tablo 3'te yer almaktadır $(5,6,35,36)$. Ağız bakımı geçici ve az düzeyde KiB'ı arttırmaktadır. Ancak bu artışın klinik olarak anlamlı olmadığı ortaya konulmuştur $(5,6,34)$. KiB değeri normal sınırlar içerisinde bulunan hastalarda, ağız bakımı güvenli bir uygulamadır $(7,36)$ ve ikincil beyin hasarına neden olmayabilir. KiB değeri yüksek olan hastalarda ağız bakımının dikkatli yapılması gerekmektedir $(5,6)$ ve ikincil beyin hasarına neden olabilir. Sınırlı sayıda çalışmaların olması, bu konunun daha fazla araştııılması gerektiğini de göstermektedir.

Vücut Banyosu: Yoğun bakım ünitelerinde uzun süre yatan hastaların hijyenik bakım gereksinimlerinden birisi de vücut banyosudur. Vücut banyosunun KiB'ı ve SPB'ı üzerine etkisini gösteren sınırlı sayıda çalışma bulunmaktadır $(1,6)$ (Tablo 4). Bu çalışmalardan birinde 93 uygulamadan yalnızca 6'sında KiB artışı, 2'sinde ise SPB'nda azalma saptanmış ve 2 hastada ortaya çıkan ikincil beyin hasarının \%30'unun bu girişimlerden kaynaklandığı bildirilmiştir (6). Diğer çalışma da ise vücut banyosu, yalnızca 3 hastada (\%17) KiB artışına ve ikincil beyin hasarına yol açmışır (1). Yoğun bakım ünitelerinde sık uygulanan bu hemşirelik girişiminin etkisini gösteren daha fazla çalışmaya gereksinim duyulmaktadır.

Hemşirelik Girişimlerinin Bir Araya Gelmesi: Hemşirelik bakım girişimlerinin aynı zaman diliminde uygulanması (hastaya yeniden pozisyon verme ile diğer girişimlerin eş zamanlı uygulanması gibi); KiB artışına bağlı ikincil beyin hasarına neden olabilmektedir (28). Hemşirelik girişimlerinin bir araya toplanması arteriyel kan basıncında artışa neden

Tablo 3. Ağız bakımının kafa içi basınç ve serebral perfüzyon basıncı üzerine etkisini inceleyen çalışmalar

\begin{tabular}{|c|c|c|c|c|}
\hline Çalışma & $\begin{array}{l}\text { Çalışmanın } \\
\text { Yöntemi }\end{array}$ & $\begin{array}{l}\text { Kanıt } \\
\text { Düzeyi }\end{array}$ & $\begin{array}{c}\text { Öneri } \\
\text { Derecesi }\end{array}$ & Çalışma Sonuçları \\
\hline Predergast ve ark. (35) & $\begin{array}{l}\text { Klinik deneysel } \\
\text { çalışma } \\
\text { (45 hasta) }\end{array}$ & $2 a$ & B & $\begin{array}{l}\text { Çalışmada, çocuk diş fırçası ya da sünger çubuklarla uygulanan ağız bakımının KiB } \\
\text { üzerine etkisi araştırımıştır. Ağız bakımının KiB üzerinde anlamlı bir etkisinin olmadığı } \\
\text { ancak KiB'ının } 20 \text { mmHg üzerinde olan } 13 \text { hastanın 3'ünde, KiB'ının ağız bakımı } \\
\text { sonrasında } 30 \text { dakika yüksek kaldığı bildirilmiştir. }\end{array}$ \\
\hline Predergast ve ark. (36) & $\begin{array}{l}\text { Randomize } \\
\text { kontrollü çalışma } \\
\text { (27 hasta) }\end{array}$ & $1 b$ & A & $\begin{array}{l}\text { Çalışmada manuel diş fırçası veya elektrikli diş fırçası ile uygulanan ağız bakımının } \\
\text { KiB ve SPB üzerine etkisi araştııımıştır. Uygulanan ağız bakımı yöntemleri sırasında } \\
\text { KiB ve SPB değişiklikleri arasında bir fark olmadığı, ağız bakımının normal KiB'ı olan } \\
\text { hastalarda güvenli bir uygulama olduğu bildirilmiştir. }\end{array}$ \\
\hline Nyholm ve ark. (6) & $\begin{array}{l}\text { Kantitatif prospektif } \\
\text { gözlem çalışması } \\
\text { (18 hasta) }\end{array}$ & 3 & C & $\begin{array}{l}\text { Çalışmada manuel diş fırçası ile uygulanan ağız bakımının KiB ve SPB üzerine etkisi } \\
\text { araştıııımışırı. Hastalara } 171 \text { defa ağız bakımı uygulanmış, } 5 \text { girişim KiB'ta artışa ve } \\
1 \text { girişim SPB'nda azalmaya neden olmuştur. }\end{array}$ \\
\hline Szabo ve ark. (5) & $\begin{array}{c}\text { Gözlemsel çalışma } \\
\text { (23 hasta) }\end{array}$ & 3 & C & $\begin{array}{l}\text { Çalışmada manuel diş fırçası ile uygulanan ağız bakımının KiB ve SPB üzerine etkisi } \\
\text { araştııımışır. Ağız bakımı uygulaması sırasında ve sonrasında geçici KiB artışı ve } \\
\text { SPB'nda azalma olduğu ancak bunun klinik olarak anlamlı olmadığı bildirilmiştir. }\end{array}$ \\
\hline
\end{tabular}

Tablo 4. Vücut Banyosunun kafa içi basınç ve serebral perfüzyon basıncı üzerine etkisini inceleyen çalışmalar

\begin{tabular}{|c|c|c|c|c|}
\hline Çalışma & $\begin{array}{c}\text { Çalışmanın } \\
\text { Yöntemi }\end{array}$ & $\begin{array}{l}\text { Kanit } \\
\text { Düzeyi }\end{array}$ & $\begin{array}{c}\text { Öneri } \\
\text { Derecesi }\end{array}$ & Çalışma Sonuçları \\
\hline Nyholm ve ark. (6) & $\begin{array}{l}\text { Kantitatif prospektif } \\
\text { gözlem çalışması } \\
\text { (18 hasta) }\end{array}$ & 3 & C & $\begin{array}{l}\text { Çalışmada vücut banyosunun KiB ve SPB'ı üzerine etkisi araştırılmıştır. Hastalara } \\
93 \text { defa vücut banyosu uygulanmış, } 6 \text { girişim KiB'ta artışa, } 2 \text { girişim ise SPB'nda } \\
\text { azalmaya neden olmuştur. Dokuz ve } 16 \text { numaralı hastalarda görülen ikincil beyin } \\
\text { hasarının \%30'unun hijyenik girişimlerden kaynaklandığı bildirilmiştir. }\end{array}$ \\
\hline Nyholm ve ark. (1) & $\begin{array}{l}\text { Kantitatif prospektif } \\
\text { gözlemsel çalışma } \\
\text { (28 hasta) }\end{array}$ & 3 & C & $\begin{array}{l}\text { Çalışmada vücut banyosunun KiB üzerine etkisi araştırılmıştır. Vücut banyosunun } \\
3 \text { hastada KiB artışına neden olduğu ve bu artışın ikincil hasara neden olabileceği } \\
\text { bildirilmiştir. }\end{array}$ \\
\hline
\end{tabular}


olarak beyne giden kan akımını arttırmaktadır. Beyne giden kan akımındaki artış, KiB artışına neden olur $(6,28)$.

Hemşirelik girişimlerine bağlı ikincil beyin hasarının önlenmesi amacıyla, hemşirelik girişimleri bir araya toplanmamalı, hemşirelik girişimleri süresince hastanı KIB'ın 25 mmHg'nın üstüne çıkmaması ve KiB değerinin 5 dakika içinde işlem öncesi değerine dönmesine özen gösterilmelidir. Uygulanacak hemşirelik girişimleri arasında dinlenme süreleri planlanmalıdır $(3,6,28)$. Hemşirelik girişimlerinin bir araya gelmesinin KIB ve SPB üzerine etkisini inceleyen yalnızca bir çalışma (6) bulunması bu konunun daha fazla irdelenmesi gerektiğini göstermektedir.

\section{Kaynaklar}

1. Nyholm L, Howells T, Enblad P. Predictive factors that may contribute to secondary insults with nursing interventions in adults with traumatic brain injury. J Neurosci Nurs 2017;49:49-55. [CrossRef]

2. Altun Uğraş G. Kafa içi basınç artışı ve hemşirelik bakımı. İ̧̧inde: Öztekin SD, editör. Nöroşirürji Hemşireliği. İstanbul: Nobel Tıp Kitapevi; 2015. ss.29-49.

3. Altun Uğraş $G$, Yüksel $S$. Factors affecting intracranial pressure and nursing interventions. Jacobs J Nurs Care 2014;1:1-5.

4. Öztekin SD, Öztekin I. Kafa Travmaları: Fiziksel Tanılama Tedavi ve Bakımda Temel İlkeler. İçinde: Öztekin SD. Nöroşirürji Hemşireliğii. İstanbul: Nobel Tıp Kitapevi 2015:53-86.

5. Szabo CM, Grap MJ, Munro CL, Starkweather A, Merchant RE. The effect of oral care on intracranial pressure in critically ill adults. J Neurosci Nurs 2014;46:321-9. [CrossRef]

6. Nyholm L, Steffansson E, Fröjd C, Enblad P. Secondary insults related to nursing interventions in neurointensive care: a descriptive pilot study. J Neurosci Nurs 2014;46:285-91. [CrossRef]

7. McNett MM, Olson DM. Evidence to guide nursing interventions for critically ill neurologically impaired patients with ICP monitoring. J Neurosci Nurs 2013;45:120-3. [CrossRef]

8. Savcı C, Kaya H, Acaroğlu R, Kaya N, Bilir A, Kahraman H, Gökerler N. Nöroloji ve nöroşirürji kliniklerinde hastaların düşme riski ve alınan önlemlerin belirlenmesi. Maltepe Üniv Hemşirelik Bilim ve Sanatı Dergisi 2009;2:19-25.

9. Szabo CM. The effect of oral care on intracranial pressure: a review of the literature. J Neurosci Nurs 2011;43:E1-9. [CrossRef]

10. Galbiati G, Paola C. Effect of open and closed endotracheal suctioning on intracranial pressure and cerebral perfusion pressure in adult patients with severe brain injury: a literature review. J Neurosci Nurs 2015;47:239-46. [CrossRef]

11. Altun Uğraş G, Aksoy $G$. The effects of open and closed endotracheal suctioning on intracranial pressure and cerebral perfusion pressure: a crossover, single-blind clinical trial. J Neurosci Nurs 2012;44:E1-8. [CrossRef]

12. Carney N, Totten A, O'Reilly C, Ullman JS, Hawryluk GW, Bell MJ, et al. Guidelines for the management of severe traumatic brain injury, fourth edition. Neurosurgery 2017;80:6-15. [CrossRef]

13. Brain Trauma Foundation, American Association of Neurological Surgeons, Congress of Neurological Surgeons. Guidelines for the management of severe traumatic brain injury. J Neurotrauma 2007;24:S1-106. [CrossRef]

\section{Sonuç}

Sonuç olarak, birçok hemşirelik girişimi KiB artışına ve SPB'ında azalmaya neden olabilmektedir. Ancak hemşirelik girişimlerinin ikincil beyin hasarına neden olduğunu gösteren sınırlı sayıda çalışma bulunmaktadır. Nöroşirürji hastalarının tedavi ve hemşirelik bakım girişimleri kanıt temelli uygulamalar doğrultusunda gerçekleştirildiğinde, ikincil beyin hasarları önlenebilmektedir. KiB artışı ve SPB'ında düşme riski yüksek olan hastalarda, uygulanan hemşirelik girişimlerinin ikincil beyin hasarına etkisine yönelik daha fazla çalışmaların yapılması ve sonuçlarının ortaya konulması önemlidir.

14. Gemma M, Tommasino C, Cerri M, Giannotti A, Piazzi B, Borghi T. Intracranial effects of endotracheal suctioning in the acute phase of head injury. J Neurosurg Anesthesiol 2002;14:50-4. [CrossRef]

15. Bourgault AM, Brown CA, Hains SM, Parlow JL. Effects of endotracheal tube suctioning on arterial oxygen tension and heart rate variability. Biol Res Nurs 2006;7:268-78. [CrossRef]

16. Özden D, Görgülü RS. Effects of open and closed suction systems on the haemodynamic parameters in cardiac surgery patients. Nurs Crit Care 2015;20:118-25. [CrossRef]

17. Thiesen RA, Dragosavac D, Roquejani AC, Falcão ALE, Araujo S, Dantas-Filho VP, et al. Influence of the respiratory physiotherapy on intracranial pressure in severe head trauma patients. Arq Neuropsiquiatr 2005;63:110-3. [CrossRef]

18. Leone M, Abanese J, Viviand X, Garnier F, Bourgoin A, Barrau K, Martin C.. The effects of reminfentanil on endotracheal suctioninginduced increases in intracranial pressure in head-injured patients. Anesth Analg 2004;99:1193-8. [CrossRef]

19. Chivite Fernández N, Martinez Oroz A, Marraco Bonmcompte M, Navarro García MA, Nuin ES, Gomez de Segura Nieva JL, Bermejo Fraile B. Intracranial pressure response during secretion aspiration after administration of a muscle relaxant. Enferm Intensiva 2004;16:143-52.

20. Bilotta F, Branca G, Lam A, Cuzzone V, Doronzio A, Rosa G. Endotracheal lidocaine in preventing endotracheal suctioninginduced changes in cerebral hemodynamics in patients with severe head trauma. Neurocrit Care 2008;8:241-6. [CrossRef]

21. Hickey JV, Olson DM, Turner DA. Intracranial pressure waveform analysis during rest and suctioning. Biol Res Nurs 2009;11:174-86. [CrossRef]

22. Gholamzadeh S, Javadi M. Effect of endotracheal suctioning on intracranial pressure in severe head-injured patients. Crit Care 2009;13:1-2. [CrossRef]

23. Nemer S, Barbas C, Caldeira J, Guimaraes B, Azeredo L, Gago R, Souza $P C P$. Evaluation of maximal inspiratory pressure, tracheal airway occlusion pressure, and its ration in the weaning outcome. Crit Care 2009;24:441-6. [CrossRef]

24. Cerqueira-Neto ML, Moura ÀV, Scola RH, Aquim EE, Rea-Neto À, Oliveira MC, Cerqueira TCF. The effect of breath physiotherapeutic maneuvers on cerebral hemodynamics. Arq Neuropsiquiatr 2010;68:567-72. [CrossRef]

25. Mathieu A, Guillon A, Leyre S, Martin F, Fusciardi J, Laffon M. Aerosolized lidocaine during invasive mechanical ventilation: invitro characterization and clinical efficiency to prevent systemic and cerebral hemodynamic changes induced by endotracheal suctioning in head-injured patients. J Neurosurg Anesthesiol 2013;25:8-15. [CrossRef] 
26. Ledwith MB, Bloom S, Maloney-Wilensky E, Coyle B, Polomano $\mathrm{RC}$, Le Roux PD. Effect of body position on cerebral oxygenation and physiologic parameters in patients with acute neurological conditions. J Neurosci Nurs 2010;42:280-7. [CrossRef]

27. Weaver DL, Bradford JL. Neurologic System Function, Assessment and Therapeutic Measures. In: Williams LS, Hooper PD, editors. Understanding Medical Surgical Nursing, 5th ed. Philadelphia: FA Davis Company; 2015. pp.1095-210.

28. Hickey JV, Olson DM. Intracranial hipertension: theory and management of increased intracranial pressure. In: Hickey JV, editor. The Clinical Practice of Neurological and Neurosurgical Nursing, 6th ed. USA: Wolters Kluwer Health, Lippincott Williams \& Wilkins; 2009. pp.270-307.

29. Barker E. Intracranial pressure and monitoring. In: Barker E, editor. Neuroscience Nursing, a Spectrum of Care, 3rd ed. St. Louis: Mosby Elsevier; 2008. pp.305-36.

30. Ng I, Lim J, Wong HB. Effects of head posture on cerebral hemodynamics: its influences on intracranial pressure, cerebral perfusion pressure, and cerebral oxygenation. Neurosurgery 2004;54:593-8. [CrossRef]
31. Palazón JH, Asensi PD, López SB, Bautista FP, Candel AG. Effect of head elevation on intracranial pressure, cerebral perfusion pressure and regional cerebral oxygen saturation in patients with cerebral hemorrhage. Rev Esp Anestesiol Reanim 2008;55:289-93.

32. Kose $G$, Hatipoglu S. Effect of headand body positioning on cerebral blood flow velocity in patients who underwent cranial surgery. J Clin Nurs 2012;21:1859-67. [CrossRef]

33. Jiang Y, Ye Z, You C, Hu X, Liu Y, Li H, et al. Systematic review of decreased intracranial pressure with optimal head elevation in post craniotomy patients: a meta-analysis. J Adv Nurs 2015;71;10:223746. [CrossRef]

34. Yüksel S, Altun Uğraş G. Nöroşirürji hastalarında ağız bakımı kafa içi basıncı etkiler mi? Türk Nöroşirürji Derg 2015;Ek sayı:494.

35. Prendergast $V$, Hallberg IR, Jahnke $H$, Kleiman $C$, Hagell P. Oral health, ventilator-associated pneumonia, and intracranial pressure in intubated patients in a neuroscience intensive care unit. Am J Crit Care 2009;18:368-76. [CrossRef]

36. Prendergast $V$, Hagell $P$, Hallberg IR. Electric versus manual tooth brushing among neuroscience ICU patients: is it safe? Neurocrit Care 2011;14:281-6. [CrossRef] 